\title{
Evaluating object recognition ability in developmental prosopagnosia using the Cambridge Car Memory Test
}

Article

Accepted Version

Gray, K. L. H., Biotti, F. and Cook, R. (2019) Evaluating object recognition ability in developmental prosopagnosia using the Cambridge Car Memory Test. Cognitive Neuropsychology, 36 (1-2). pp. 89-96. ISSN 1464-0627 doi:

https://doi.org/10.1080/02643294.2019.1604503 Available at https://centaur.reading.ac.uk/83174/

It is advisable to refer to the publisher's version if you intend to cite from the work. See Guidance on citing.

To link to this article DOI: http://dx.doi.org/10.1080/02643294.2019.1604503

Publisher: Taylor \& Francis

All outputs in CentAUR are protected by Intellectual Property Rights law, including copyright law. Copyright and IPR is retained by the creators or other copyright holders. Terms and conditions for use of this material are defined in the End User Agreement.

www.reading.ac.uk/centaur 
Central Archive at the University of Reading

Reading's research outputs online 
In press at: Cognitive Neuropsychology

Format: Research Article

Running head: Object recognition in developmental prosopagnosia

Word count: 3425

\title{
Evaluating object recognition ability in developmental prosopagnosia using the Cambridge Car Memory Test
}

\author{
Katie L.H. Gray ${ }^{1}$, Federica Biotti ${ }^{2}, \&$ Richard Cook $^{3 *}$ \\ ${ }^{1}$ School of Psychology and Clinical Language Sciences, \\ University of Reading, Reading, U.K. \\ ${ }^{2}$ Department of Psychology, \\ Royal Holloway, University of London, Egham, U.K. \\ ${ }^{3}$ Department of Psychological Sciences, \\ Birkbeck, University of London, London, U.K. \\ *Corresponding author \\ Dr Richard Cook \\ Department of Psychological Sciences, \\ Birkbeck, University of London, \\ London, UK richard.cook@bbk.ac.uk
}




\begin{abstract}
Individuals with developmental prosopagnosia (DP) sometimes experience object identification difficulties in addition to problems recognising faces. To better understand the distribution of non-face object recognition ability in this population, we administered the Cambridge Car Memory Test (CCMT) - a leading, standardised measure of object recognition ability - to a large sample of DPs $(\mathrm{N}=46)$. When considered as a single group, the DPs scored lower than matched controls. This finding provides further evidence that developmental object agnosia (DOA) may be more common in DP than in the general population. Relative to the DPs' face recognition deficits, however, car matching deficits were small and inconsistent. In fact, we observed a striking range of CCMT performance in our DP sample. While some DPs performed extremely poorly, many more achieved scores within one standard deviation of the typical mean, and several DP participants achieved excellent CCMT scores comparable with the best controls.
\end{abstract}

\title{
Keywords:
}

Developmental prosopagnosia; Face recognition; Object recognition; Independent disorders hypothesis; Cambridge Car Memory Test 


\section{Introduction}

Developmental prosopagnosia (DP) is a neurodevelopmental condition associated with difficulties recognising familiar faces and distinguishing unfamiliar faces, that occurs in people with normal intelligence and typical visual acuity, and in the absence of manifest brain injury (Behrmann \& Avidan, 2005; Duchaine \& Nakayama, 2006b; Susilo \& Duchaine, 2013). DP often runs in families indicating that the condition may have a genetic component (Duchaine, Germine, \& Nakayama, 2007; Johnen et al., 2014; Schmalzl, Palermo, \& Coltheart, 2008). Individuals with DP identify others using non-face cues (e.g., hairstyle voice, and gait) and often experience great difficulty when familiar people are met in unusual contexts or when they alter their appearance (Cook \& Biotti, 2016; Shah, Gaule, Sowden, Bird, \& Cook, 2015). Historically, the condition was thought to be rare (McConachie, 1976), but current estimates suggest that $2 \%$ of the general population may experience face recognition difficulties severe enough to disrupt their daily lives (Kennerknecht et al., 2006; Kennerknecht, Ho, \& Wong, 2008).

The origins of DP remain poorly understood. Cognitive theories have argued that individuals with DP may be less able to integrate information from disparate facial regions to form unified perceptual descriptions relative to typical observers (Avidan, Tanzer, \& Behrmann, 2011; DeGutis, Cohan, \& Nakayama, 2014; Palermo et al., 2011). Many DPs, however, appear to exhibit typical markers of 'holistic face processing' (Biotti, Wu, et al., 2017; Le Grand et al., 2006; Susilo et al., 2010). At the neurological level, studies have revealed reduced grey matter volume in occipitotemporal cortex of individuals with DP (Behrmann, Avidan, Gao, \& Black, 2007; Garrido et al., 2009) and have suggested atypical functional connectivity in high-level visual areas (Avidan \& Behrmann, 2009; Lohse et al., 2016; Rosenthal et al., 2017). Recent studies also suggest that reduced density and coherence of the inferior longitudinal fasciculus, a white matter tract connecting the occipital and temporal lobes, may impair information exchange within the face processing network in DP (Gomez et al., 2015; Song et al., 2015; Thomas et al., 2009).

In addition to their characteristic face recognition difficulties, some individuals with DP also exhibit signs of co-occurring object recognition difficulties. Individuals have been described, for example, who experience problems identifying cars (e.g., Biotti, Gray, \& Cook, 2017; De Haan \& Campbell, 1991; Duchaine, Germine, et al., 2007; Duchaine \& Nakayama, 2005; Klargaard, Starrfelt, \& Gerlach, 2018), bicycles (e.g., Dalrymple \& Duchaine, 2014), guns 
(e.g., Duchaine, Germine, et al., 2007; Duchaine \& Nakayama, 2005), flowers (e.g., De Haan \& Campbell, 1991), scenes (e.g., Duchaine \& Nakayama, 2005), animals and tools (e.g., Duchaine \& Nakayama, 2005; Gerlach, Klargaard, \& Starrfelt, 2016). Some authors have argued that the incidence of object recognition difficulties in the DP population is so high, that the condition can be understood only in terms of a domain-general perceptual deficit (Gerlach et al., 2016; Geskin \& Behrmann, 2017). One possibility is that DP is a developmental form of integrative agnosia, whereby individuals are unable integrate component parts into a coherent whole, that impairs both face and object recognition (e.g., Riddoch \& Humphreys, 1987). A closely-related idea is that individuals with DP may experience delayed or impoverished processing of global shape information (Avidan et al., 2011; Gerlach \& Starrfelt, 2018; Tanzer, Freud, Ganel, \& Avidan, 2013).

Other authors reject the view that object recognition problems are a universal feature of DP. According to the independent disorders hypothesis (IDH; Gray \& Cook, 2018), DP and developmental object agnosia (DOA) are best thought of as independent neurodevelopmental conditions that sometimes co-occur. A key prediction of this hypothesis is the existence of 'pure' cases of DP and DOA; individuals who experience impaired face recognition, but typical object recognition, and vice versa. Consistent with this view, some DPs exhibit apparently typical object recognition (e.g., Duchaine, Yovel, Butterworth, \& Nakayama, 2006) and cases of DOA have been described where the individual exhibits apparently typical face recognition (e.g., Germine, Cashdollar, Duzel, \& Duchaine, 2011). However, the IDH also predicts that DP and DOA co-occur, that is to say, the incidence of DOA is higher in DP than in the wider population, due to common genetic or environmental risk factors (Gray \& Cook, 2018). Specifically, susceptibility to aberrant structural development of occipitotemporal cortex may be a common risk factor for DP and DOA (see also: Susilo \& Duchaine, 2013).

Both the IDH (Gray \& Cook, 2018) and domain-general accounts (Avidan et al., 2011; Gerlach \& Starrfelt, 2018; Tanzer et al., 2013) predict a degree of correlation between the face and object recognition abilities seen in large samples of observers. Under domaingeneral accounts, one would expect a tight coupling between observers' ability to identify faces and non-face objects; for example, an individual's degree of impairment with faces ought to relate closely to their degree of impairment with objects. In contrast, however, the IDH predicts a weaker, idiosyncratic relationship. Although people at risk of perceptual 
difficulties with faces may often develop co-occurring perceptual difficulties with non-face objects, this co-occurrence is not inevitable - some individuals may exhibit selective problems with either faces or objects (i.e., 'pure' cases).

In light of these conflicting views, we sought a better understanding of the object recognition difficulties seen in the DP population. To this end, we examined performance on the Cambridge Car Memory Test (CCMT; Dennett et al., 2011) in a large sample of DPs ( $=$ 46) and matched controls $(\mathrm{N}=61)$. The CCMT employs a 3-AFC match-to-sample format that mirrors that of the Cambridge Face Memory Test (CFMT; Duchaine \& Nakayama, 2006a), a standardised measure of face recognition used widely in the diagnosis of DP. In both tasks participants are asked to identify target items encountered in a study phase from a line up of three test items (target plus two lures). In both tasks, trial difficulty is varied across a 72-trial procedure through viewpoint manipulations and through the addition of highfrequency visual noise. Both the CFMT and CCMT exhibit good internal reliability; for example, $\alpha=.88$ (Bowles et al., 2009) and $\alpha=.84$ (Dennett et al., 2011), respectively. Responses are not speeded and both tests stress accuracy ${ }^{1}$.

The CCMT has been used to address a wide range of questions in cognitive neuropsychology (e.g., Esins, Schultz, Stemper, Kennerknecht, \& Bulthoff, 2016; Klargaard et al., 2018; Shah, Gaule, Gaigg, Bird, \& Cook, 2015), cognitive psychology (e.g., Dennett, McKone, Edwards, \& Susilo, 2012), neuropsychiatry (e.g., Ewbank et al., 2017), and behavioural genetics (e.g., Shakeshaft \& Plomin, 2015). To date, however, it remains unclear how DPs perform on this widely-used measure of object recognition ability. Several studies have described individual DPs who score badly on the CCMT (e.g., Klargaard et al., 2018; Palermo et al., 2017; Rivolta, Lawson, \& Palermo, 2017; Susilo et al., 2010; White, Rivolta, Burton, Al-Janabi, \& Palermo, 2017). However, previous comparison of matched samples has failed to reveal differences at the group level; for example, Shah et al. (2015; N = 15 DPs) and Esins et al. (2016; $N=16$ DPs) found that DPs' performance on the CCMT did not differ significantly from that of controls.

\section{Participants}

We describe data from 107 adults, 46 with DP (21 males; $M_{\text {age }}=39.4$ years, $S D_{\text {age }}=9.4$ years) and 61 typically developed (TD) controls (27 males; $M_{\text {age }}=37.0$ years, $S D_{\text {age }}=9.8$ years). Neither participant age $[t(105)=1.313, p=.192]$ nor proportion of males $\left[X^{2}(1)=\right.$ 
$.01, p=.888]$ differed significantly between the two groups. Ethical approval was granted by the local ethics committee. The research was conducted in line with the ethical guidelines provided by the $6^{\text {th }}$ (2008) Declaration of Helsinki. All participants provided informed consent and were fully debriefed after the experimental procedure. All participants were tested in person under controlled lab conditions. DP participants completed the CFMT first, followed by the CCMT. Wherever possible, DP participants completed the tests in a single session. Control participants completed the tests in a single session. Half of the controls completed the CFMT first, half completed the CCMT first.

DP participants were recruited through $\underline{w w w . t r o u b l e w i t h f a c e s . o r g}$ and reported lifelong face recognition difficulties in the absence of brain injury and psychiatric disorder (autism or schizophrenia). Diagnostic decisions were based primarily on participants' scores on the Twenty-Item Prosopagnosia Index (PI20; Gray, Bird, \& Cook, 2017; Shah, Gaule, Sowden, et al., 2015) and the CFMT (Duchaine \& Nakayama, 2006a). The participants with DP also completed the Cambridge Face Perception Test (CFPT; Duchaine, Germine, et al., 2007). Typical participants, recruited through local subject-pools, completed the CFMT, the CCMT, and the PI20. None of the typical controls scored more than 60 on the PI20. No-one was excluded on this basis. All members of the DP sample scored at least 2 SDs below the typical mean on the CFMT, and at least 3 SDs above the typical mean on the PI20. Summary statistics for both groups are provided in Table 1 and diagnostic information for each DP is provided as supplementary material. The use of convergent self-report evidence and scores on objective, computer-based tasks may be a particularly effective approach to the identification and classification of DP; for example, less than $1.5 \%$ of the general population score below $65 \%$ on the CFMT and more than 65 on the PI20 (Gray et al., 2017).

Table-1

\section{Results}

The data were analysed using ANOVA with Test (CFMT, CCMT) as a within-subjects factor, and Observer Sex (male, female) and Group (DP, TD) as between-subjects factors. As noted above, low CFMT scores formed an important part of the diagnostic evidence used to classify observers as DP. The fact that the DPs scored well-below typical controls on this measure is therefore entirely unsurprising. We include a Test factor (CFMT, CCMT), however, so that readers can compare the relative size of deficits seen on the face and car 
variants of this test. Previous studies have suggested an effect of observer sex on the CCMT, whereby male observers typically perform a little better than females ${ }^{2}$ (Dennett et al., 2011). We therefore included Observer Sex as a factor to determine whether this interacts with Group (TD, DP).

The analysis revealed a significant main effect of Group $\left[F(1,103)=115.194, p<.001, \eta_{\mathrm{p}}{ }^{2}=\right.$ $.528]$ and a Group $\times$ Test interaction $\left[F(1,103)=78.121, p<.001, \eta_{\mathrm{p}}^{2}=.431\right]$. While controls generally outperformed the DPs, the difference was more pronounced on the CFMT $\left(M_{\mathrm{TD}}=83.56 \%, S D_{\mathrm{TD}}=9.57 \% ; M_{\mathrm{DP}}=54.38 \% S D_{\mathrm{DP}}=7.39 \%\right)$ than on the CCMT $\left(M_{\mathrm{TD}}=\right.$ $73.52 \%, S D_{\mathrm{TD}}=12.57 \% ; M_{\mathrm{DP}}=67.36 \% S D_{\mathrm{DP}}=12.60 \%$; Figure 1a). Planned contrasts revealed significant group differences on both the CFMT $[t(105)=17.174, p<.001]$ and the $\operatorname{CCMT}[t(105)=2.506, p=.014]$. We observed no main effect of Test $[F(1,103)=1.899, p$ $\left.=.171, \eta_{\mathrm{p}}^{2}=.018\right]$, no main effect of Observer $\operatorname{Sex}\left[F(1,103)=1.973, p=.163, \eta_{\mathrm{p}}{ }^{2}=.019\right]$, nor a Test $\times$ Observer Sex $\times$ Group interaction $\left[\mathrm{F}(103)=.434, p=.512, \eta_{\mathrm{p}}^{2}=.004\right]$. However, the analysis revealed a Test $\times$ Observer Sex interaction $[F(1,103)=5.063, p$ $\left.=.027, \eta_{\mathrm{p}}{ }^{2}=.047\right]$ whereby male participants tended to score higher on the CCMT than females.

Figure-1

In light of the significant Observer Sex (male, female) $\times$ Test $($ CFMT, CCMT) interaction described above, we sought to confirm that the effect of Group on CCMT scores (TD > DP) was seen for both male (Figure 2a) and female (Figure 2b) observers. First, we compared the performance of the male controls $\left(\mathrm{N}=27, M_{\text {age }}=37.4\right.$ years, $S D_{\text {age }}=9.5$ years $)$ with the male DPs $\left(\mathrm{N}=21, M_{\text {age }}=40.5\right.$ years, $S D_{\text {age }}=10.1$ years $)$. Relative to the male controls, the male DPs were significantly impaired on both the CFMT $[t(46)=10.990, p<.001]$ and the $\operatorname{CCMT}[t(46)=2.117, p=.040]$, but disproportionately impaired at the CFMT $[F(1,46)=$ $\left.26.685, p<.001, \eta_{\mathrm{p}}^{2}=.367\right]$. Next, we compared the performance of the female controls $(\mathrm{N}$ $=34, M_{\text {age }}=36.6$ years, $S D_{\text {age }}=10.1$ years $)$ and the female DPs $\left(\mathrm{N}=25, M_{\text {age }}=38.6\right.$ years, $S D_{\text {age }}=8.9$ years). Once again we observed a highly significant group difference on the CFMT $[t(57)=13.068, p<.001]$, and a significant Group (TD, DP $) \times$ Test $($ CFMT, CCMT $)$ interaction $\left[F(1,57)=56.472, p<.001, \eta_{\mathrm{p}}^{2}=.498\right]$. When the analysis was restricted to female participants, however, the difference between the DPs and the TDs on the CCMT did not reach significance $[t(57)=1.502, p=.139]$. 
Figure-2

As expected, the variance in CFMT scores differed significantly between the DPs and controls $[F(1,105)=5.06, p=.03]$. This likely reflects the fact that the CFMT scores of the DPs were tightly constrained, whilst the CFMT scores of the controls were free to vary. The variance in CCMT scores did not differ between the two groups $[F(1,105)=.17, p=.69]$.

Having pooled the TD and DP groups to form a single combined sample $(\mathrm{N}=107$; Figure 1b), we observed a modest correlation between observers' performance on the CFMT and their scores on the CCMT $(r=.329, p<.001, \mathrm{~N}=107)$. When considered separately, this correlation was seen in the TD group ( $r=.276, p=.031, \mathrm{~N}=61)$, but did not reach significance in the DP group $(r=.215, p=.151, \mathrm{~N}=46)$, possibly reflecting the limited range of CFMT scores. The difference between these correlation coefficients was not significant [Fisher's $z=.323, p=.747$ ]. Examination of the individual differences revealed a striking range of object recognition ability in the DP group. At one end of the distribution, five individuals in the DP sample produced CCMT scores 1.64 standard deviations below the typical mean, and two produced scores 1.96 standard deviations below the typical mean. At the other extreme, however, several DPs performed very well, achieving scores comparable with the best controls (Figure 1c).

To formally explore how many of the DPs were significantly impaired on the CCMT, we performed single-case analysis (Crawford, Garthwaite, \& Ryan, 2011) to compare each DP's CCMT performance with the TD group. In this analysis, we found that 2/46 DPs were classified as having significantly lower CCMT scores than the TD group. We also explored possible dissociations between CFMT and CCMT performance (e.g., Gerlach, Lissau, \& Hildebrandt, 2018). Dissociations in performance between two tasks can be classified as putatively classical, or strong. A DP is considered to fulfil the criteria for a putatively classical dissociation when performance is significantly lower than TDs on the CFMT, but not the CCMT, and their standardised difference between the two tasks is significantly different from controls. Strong dissociations are fulfilled when a DP is significantly impaired on the CFMT and CCMT, and their standardised difference between the two tasks is significantly different from controls. In our sample of DPs, we found that 24/46 DPs met 
criteria for a putatively classical dissociation, whereas only one DP met the criteria for a strong dissociation.

\section{General Discussion}

To better understand the distribution of non-face object recognition ability in the DP population, we administered the CCMT to a large sample of DPs $(\mathrm{N}=46)$ and matched controls. Overall, we found that the DP group achieved lower scores on the CCMT than typical controls. This finding provides further evidence that object recognition difficulties may be more common in DP than in the general population. Relative to their face recognition deficits, however, the DPs' car matching deficits were small and inconsistent.

Some authors have proposed that DP is characterised by a single domain-general deficit that impairs the perception of faces and non-face objects alike (Avidan et al., 2011; Gerlach et al., 2016; Gerlach \& Starrfelt, 2018; Geskin \& Behrmann, 2017; Tanzer et al., 2013). Critically, this view predicts that individuals with DP should consistently exhibit difficulties recognising a wide range of non-face objects. For example, individuals with integrative agnosia appear to exhibit perceptual deficits for most types of complex visual object including cars (Germine et al., 2011; Moscovitch, Winocur, \& Behrmann, 1997; Riddoch \& Humphreys, 1987).

The striking range of CCMT performance seen in our DP sample is hard to reconcile with this view. While some DPs performed extremely poorly, many more achieved CCMT scores within one standard deviation of the TD mean and several DP participants exhibited excellent performance, achieving accuracy scores exceeding $90 \%$ comparable with the best controls. Typical levels of CCMT performance were common in the DP sample despite the fact that these individuals describe severe lifelong face recognition difficulties and all produced CFMT scores more than two standard deviations below the TD mean. To score well on the CCMT, observers must be able to identify complex visual objects across viewpoints, and when obscured by high-frequency visual noise. Excellent CCMT scores therefore suggests that a subset of DPs were able integrate local features and process global shape information, typically (also see: Biotti, Wu, et al., 2017; Duchaine et al., 2006; Duchaine, Yovel, \& Nakayama, 2007; Le Grand et al., 2006; Susilo et al., 2010) 
In contrast, the range of object recognition abilities seen in our DP sample accords very well with the IDH (Germine et al., 2011; Gray \& Cook, 2018). Under this account, DP and DOA are viewed as independent conditions that sometimes occur on their own as pure cases of DP and DOA, but often co-occur within the same individuals due to common risk factors (e.g., inherited susceptibility to aberrant structural development of occipitotemporal cortex; Gray \& Cook, 2018). Like domain-general accounts, the IDH predicts that the incidence of DOA is more common in DP than in the general population. Crucially, however, it predicts i) an idiosyncratic relationship between object and face processing abilities in DP, and ii) a subset of DPs with intact object perception. Both of these predictions are supported by the dataset described here.

According to the IDH, the composition of DP samples may determine whether authors find evidence of group-level object recognition deficits in DP. Where samples include high or low proportions of DPs with co-occurring DOA, authors may be more or less likely to find group differences, respectively. Smaller samples of DPs may often contain too few cases of DP with co-occurring DOA to reveal group differences on tasks such as the CCMT (Esins et al., 2016; Shah, Gaule, Gaigg, et al., 2015). The idiosyncratic nature of object recognition deficits in DP is highlighted by the absence of a significant effect of Group (DP, TD) in our female participants. Due to the inconsistency of object perception deficits, large samples of DPs may be required to detect consistently group-level effects on object recognition tasks. Where observed, however, we speculate that such differences are attributable to co-occurring DOA, not DP per se.

Compared with the CFMT, the CCMT may be less able to detect impairment at the singlecase level. One issue is that the mean score of typical controls on the CCMT $(\mathrm{M}=73.5 \%)$ is a little lower than the mean typical score on the CFMT $(\mathrm{M}=83.6 \%)$. A second issue is that the variability seen in typical scores is slightly greater on the CCMT (SD $=12.6 \%)$ than on the CFMT ( $\mathrm{SD}=9.6 \%$ ). Together, however, this means that DPs need to score $<50 \%$ to achieve a z-score of $<-1.96$. Given that the CCMT is a 3-AFC task, participants' performance therefore needs to approach chance levels in order to be classified as significantly impaired at the single-case level. Despite the fact that only a few DPs reached this threshold, the significant group difference seen on the CCMT suggests that mild deficits may be relatively common in this population (see also: Biotti, Gray, \& Cook, 2019). 
Our investigation was restricted to a single object category - cars. It remains to be seen whether similar findings emerge when DPs are tested with other types of object, or whether cars are somehow 'special' (e.g., Ćepulić, Wilhelm, Sommer, \& Hildebrandt, 2018; Richler, Wilmer, \& Gauthier, 2017). However, the present results are important because problems recognising and distinguishing cars are amongst the most commonly reported object perception deficits in DP. This stimulus class therefore appears to tax object recognition processes that are sometimes aberrant in DP. Moreover, the CCMT has an identical format to the CFMT, a measure that is known to reveal the perceptual problems DPs experience with faces, and is just as challenging. The failure to observe clear, widespread object recognition deficits in our large DP sample cannot therefore be attributed to the particular stimulus class used, the format of the test, or the fact the task is easier. 


\section{Footnotes}

${ }^{1}$ The versions of the CFMT and CCMT employed here do not record response latencies.

${ }^{2}$ Dennett and colleagues speculate that this may reflect the fact that male observers sometimes have greater knowledge of existing car manufacturers and models. 


\section{References}

Avidan, G., \& Behrmann, M. (2009). Functional MRI reveals compromised neural integrity of the face processing network in congenital prosopagnosia. Current Biology, 19(13), 1146-1150.

Avidan, G., Tanzer, M., \& Behrmann, M. (2011). Impaired holistic processing in congenital prosopagnosia. Neuropsychologia, 49(9), 2541-2552.

Behrmann, M., \& Avidan, G. (2005). Congenital prosopagnosia: face-blind from birth. Trends in Cognitive Sciences, 9(4), 180-187.

Behrmann, M., Avidan, G., Gao, F., \& Black, S. (2007). Structural imaging reveals anatomical alterations in inferotemporal cortex in congenital prosopagnosia. Cerebral Cortex, 17(10), 2354-2363.

Biotti, F., Gray, K. L., \& Cook, R. (2019). Is developmental prosopagnosia best characterised as an apperceptive or mnemonic condition? Neuropsychologia, 124, 285-298.

Biotti, F., Gray, K. L. H., \& Cook, R. (2017). Impaired body perception in developmental prosopagnosia. Cortex, 93, 41-49.

Biotti, F., Wu, E., Yang, H., Jiahui, G., Duchaine, B., \& Cook, R. (2017). Normal composite face effects in developmental prosopagnosia. Cortex, 95, 63-76.

Bowles, D. C., McKone, E., Dawel, A., Duchaine, B., Palermo, R., Schmalzl, L., .. . Yovel, G. (2009). Diagnosing prosopagnosia: effects of ageing, sex, and participant-stimulus ethnic match on the Cambridge Face Memory Test and Cambridge Face Perception Test. Cognitive Neuropsychology, 26(5), 423-455.

Ćepulić, D. B., Wilhelm, O., Sommer, W., \& Hildebrandt, A. (2018). All categories are equal, but some categories are more equal than others: The psychometric structure of object and face cognition. Journal of Experimental Psychology: Learning, Memory, and Cognition, 44(8), 1254-1268.

Cook, R., \& Biotti, F. (2016). Developmental prosopagnosia. Current Biology, 26(8), R312R313.

Crawford, J. R., Garthwaite, P. H., \& Ryan, K. (2011). Comparing a single case to a control sample: Testing for neuropsychological deficits and dissociations in the presence of covariates. Cortex, 47, 1166-1178.

Dalrymple, K. A., \& Duchaine, B. (2014). Impaired face detection may explain some but not all cases of developmental prosopagnosia. Developmental Science, 19, 440-451.

De Haan, E. H., \& Campbell, R. (1991). A fifteen year follow-up of a case of developmental prosopagnosia. Cortex, 27(4), 489-509.

DeGutis, J., Cohan, S., \& Nakayama, K. (2014). Holistic face training enhances face processing in developmental prosopagnosia. Brain, 137(Pt 6), 1781-1798. 
Dennett, H. W., McKone, E., Edwards, M., \& Susilo, T. (2012). Face aftereffects predict individual differences in face recognition ability. Psychological Science, 23(11), 1279-1287.

Dennett, H. W., McKone, E., Tavashmi, R., Hall, A., Pidcock, M., Edwards, M., \& Duchaine, B. (2011). The Cambridge Car Memory Test: a task matched in format to the Cambridge Face Memory Test, with norms, reliability, sex differences, dissociations from face memory, and expertise effects. Behavior Research Methods, 44(2), 587605.

Duchaine, B., Germine, L., \& Nakayama, K. (2007). Family resemblance: ten family members with prosopagnosia and within-class object agnosia. Cognitive Neuropsychology, 24(4), 419-430.

Duchaine, B., \& Nakayama, K. (2005). Dissociations of face and object recognition in developmental prosopagnosia. Journal of Cognitive Neuroscience, 17(2), 249-261.

Duchaine, B., \& Nakayama, K. (2006a). The Cambridge Face Memory Test: results for neurologically intact individuals and an investigation of its validity using inverted face stimuli and prosopagnosic participants. Neuropsychologia, 44, 576-585.

Duchaine, B., \& Nakayama, K. (2006b). Developmental prosopagnosia: a window to contentspecific face processing. Current Opinion in Neurobiology, 16, 166-173.

Duchaine, B., Yovel, G., Butterworth, E., \& Nakayama, K. (2006). Prosopagnosia as an impairment to face-specific mechanisms: Elimination of the alternative hypotheses in a developmental case. Cognitive Neuropsychology, 23(5), 714-747.

Duchaine, B., Yovel, G., \& Nakayama, K. (2007). No global processing deficit in the Navon task in 14 developmental prosopagnosics. Social, Cognitive, and Affective Neuroscience, 2(2), 104-113.

Esins, J., Schultz, J., Stemper, C., Kennerknecht, I., \& Bulthoff, I. (2016). Face perception and test reliabilities in congenital prosopagnosia in seven tests. I Perception, 7(1), 2041669515625797.

Ewbank, M. P., Pell, P. J., Powell, T. E., von dem Hagen, E. A. H., Baron-Cohen, S., \& Calder, A. J. (2017). Repetition suppression and memory for faces is reduced in adults with autism spectrum conditions. Cerebral Cortex, 27(1), 92-103.

Garrido, L., Furl, N., Draganski, B., Weiskopf, N., Stevens, J., Tan, G. C., . . Duchaine, B. (2009). Voxel-based morphometry reveals reduced grey matter volume in the temporal cortex of developmental prosopagnosics. Brain, 132(Pt 12), 3443-3455.

Gerlach, C., Klargaard, S. K., \& Starrfelt, R. (2016). On the relation between face and object recognition in developmental prosopagnosia: no dissociation but a systematic association. PLoS One, 11(10), e0165561.

Gerlach, C., Lissau, C. H., \& Hildebrandt, N. K. (2018). On defining and interpreting dissociations. Cognitive Neuropsychology, 35(1-2), 66-69. 
Gerlach, C., \& Starrfelt, R. (2018). Delayed processing of global shape information is associated with weaker top-down effects in developmental prosopagnosia. Cognitive Neuropsychology.

Germine, L., Cashdollar, N., Duzel, E., \& Duchaine, B. (2011). A new selective developmental deficit: Impaired object recognition with normal face recognition. Cortex, 47(5), 598-607.

Geskin, J., \& Behrmann, M. (2017). Congenital prosopagnosia without object agnosia? A literature review. Cognitive Neuropsychology, 22, 1-51.

Gomez, J., Pestilli, F., Witthoft, N., Golarai, G., Liberman, A., Poltoratski, S., . . GrillSpector, K. (2015). Functionally defined white matter reveals segregated pathways in human ventral temporal cortex associated with category-specific processing. Neuron, 85(1), 216-227.

Gray, K. L. H., Bird, G., \& Cook, R. (2017). Robust associations between the 20-item prosopagnosia index and the Cambridge Face Memory Test in the general population. Royal Society Open Science, 4(3), 160923.

Gray, K. L. H., \& Cook, R. (2018). Should developmental prosopagnosia, developmental body agnosia, and developmental object agnosia be considered independent neurodevelopmental conditions? Cognitive Neuropsychology, 35(1-2), 59-62.

Johnen, A., Schmukle, S. C., Hüttenbrink, J., Kischka, C., Kennerknecht, I., \& Dobel, C. (2014). A family at risk: Congenital prosopagnosia, poor face recognition and visuoperceptual deficits within one family. Neuropsychologia, 58, 52-63.

Kennerknecht, I., Grüter, T., Welling, B., Wentzek, S., Horst, J., Edwards, S., \& Grüter, M. (2006). First report of prevalence of non-syndromic hereditary prosopagnosia (HPA). American Journal of Medical Genetics, 140A(15), 1617-1622.

Kennerknecht, I., Ho, N. Y., \& Wong, V. C. N. (2008). Prevalence of heriditary prosopagonsia (HPA) in Hong Kong Chinese population. American Journal of Medical Genetics, 146A(22), 2863-2870.

Klargaard, S. K., Starrfelt, R., \& Gerlach, C. (2018). Inversion effects for faces and objects in developmental prosopagnosia: A case series analysis. Neuropsychologia, 113, 52-60.

Le Grand, R., Cooper, P. A., Mondloch, C. J., Lewis, T. L., Sagiv, N., de Gelder, B., \& Maurer, D. (2006). What aspects of face processing are impaired in developmental prosopagnosia? Brain and Cognition, 61(2), 139-158.

Lohse, M., Garrido, L., Driver, J., Dolan, R. J., Duchaine, B. C., \& Furl, N. (2016). Effective connectivity from early visual cortex to posterior occipitotemporal face areas supports face selectivity and predicts developmental prosopagnosia. Journal of Neuroscience, $36(13), 3821-3828$.

McConachie, H. R. (1976). Developmental prosopagnosia. A single case report. Cortex, 12(1), 76-82. 
Palermo, R., Rossion, B., Rhodes, G., Laguesse, R., Tez, T., Hall, B., . . Irons, J. (2017). Do people have insight into their face recognition abilities? Quarterly Journal of Experimental Psychology, 70(2), 218-233.

Palermo, R., Willis, M. L., Rivolta, D., McKone, E., Wilson, C. E., \& Calder, A. J. (2011). Impaired holistic coding of facial expression and facial identity in congenital prosopagnosia. Neuropsychologia, 49(5), 1226-1235.

Richler, J. J., Wilmer, J. B., \& Gauthier, I. (2017). General object recognition is specific: Evidence from novel and familiar objects. Cognition, 166, 42-55.

Riddoch, M. J., \& Humphreys, G. W. (1987). A case of integrative visual agnosia. 110(6), 1431-1462.

Rivolta, D., Lawson, R. P., \& Palermo, R. (2017). More than just a problem with faces: altered body perception in a group of congenital prosopagnosics. Quarterly Journal of Experimental Psychology, 70(2), 276-286.

Rosenthal, G., Tanzer, M., Simony, E., Hasson, U., Behrmann, M., \& Avidan, G. (2017). Altered topology of neural circuits in congenital prosopagnosia. Elife, 6.

Schmalzl, L., Palermo, R., \& Coltheart, M. (2008). Cognitive heterogeneity in genetically based prosopagnosia: a family study. Journal of Neuropsychology, 2(1), 99-117.

Shah, P., Gaule, A., Gaigg, S. B., Bird, G., \& Cook, R. (2015). Probing short-term face memory in developmental prosopagnosia. Cortex, 64, 115-122.

Shah, P., Gaule, A., Sowden, S., Bird, G., \& Cook, R. (2015). The 20-item prosopagnosia index (PI20): a self-report instrument for identifying developmental prosopagnosia. Royal Society Open Science, 2(6), 140343.

Shakeshaft, N. G., \& Plomin, R. (2015). Genetic specificity of face recognition. Proceedings of the National Academy of Sciences of the United States of America, 112(41), 1288712892.

Song, S., Garrido, L., Nagy, Z., Mohammadi, S., Steel, A., Driver, J., . . Furl, N. (2015). Local but not long-range microstructural differences of the ventral temporal cortex in developmental prosopagnosia. Neuropsychologia, 78, 195-206.

Susilo, T., \& Duchaine, B. (2013). Advances in developmental prosopagnosia research. Current Opinion in Neurobiology, 23, 423-429.

Susilo, T., McKone, E., Dennett, H., Darke, H., Palermo, R., Hall, A., . . Rhodes, G. (2010). Face recognition impairments despite normal holistic processing and face space coding: evidence from a case of developmental prosopagnosia. Cognitive Neuropsychology, 27(8), 636-664.

Tanzer, M., Freud, E., Ganel, T., \& Avidan, G. (2013). General-holistic impairment in congenital prosopagnosia: Evidence from Garner's speeded-classification task. Cognitive Neuropsychology, 30(6), 429-445. 
Thomas, C., Avidan, G., Humphreys, K., Jung, K. J., Gao, F., \& Behrmann, M. (2009). Reduced structural connectivity in ventral visual cortex in congenital prosopagnosia. Nature Neuroscience, 12(1), 29-31.

White, D., Rivolta, D., Burton, A. M., Al-Janabi, S., \& Palermo, R. (2017). Face matching impairment in developmental prosopagnosia. Quarterly Journal of Experimental Psychology, 70(2), 287-297. 


\section{Figure 1}
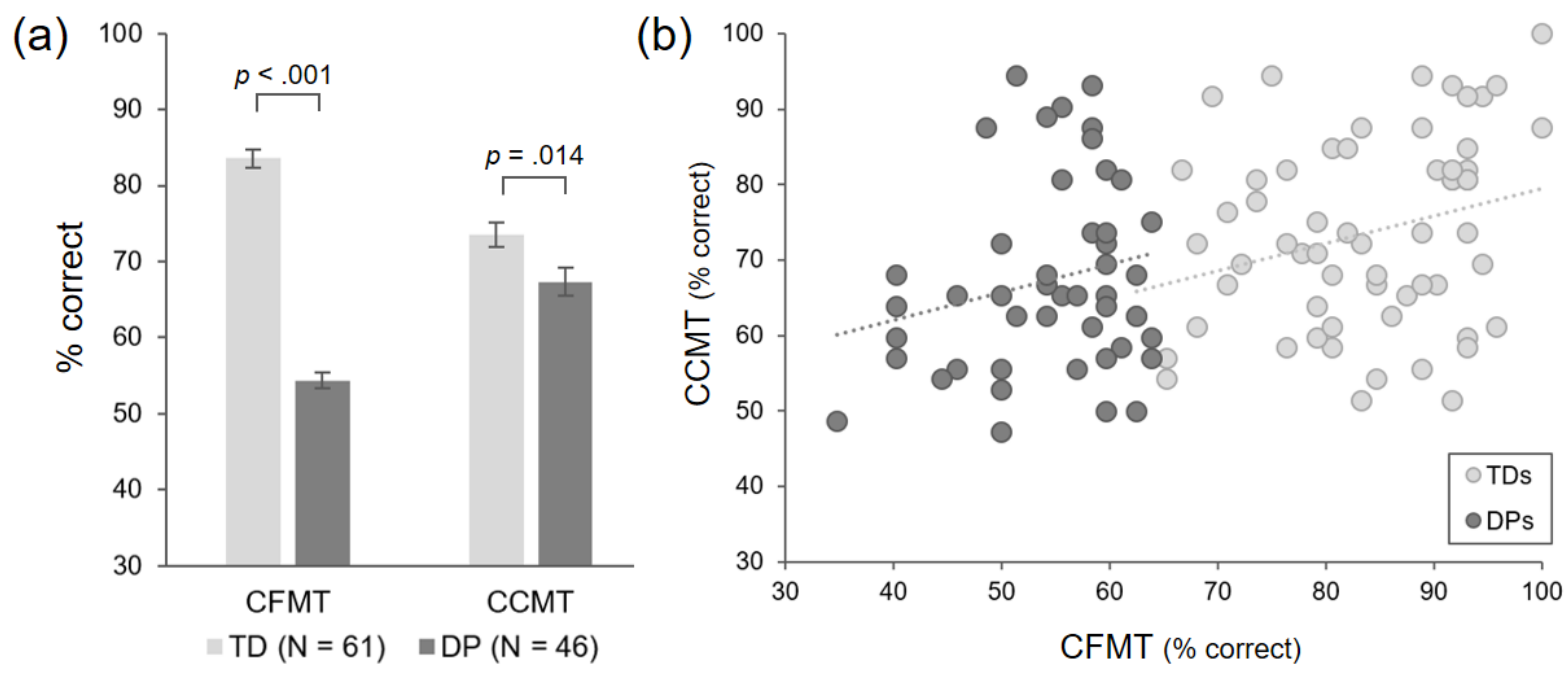

(c) 2

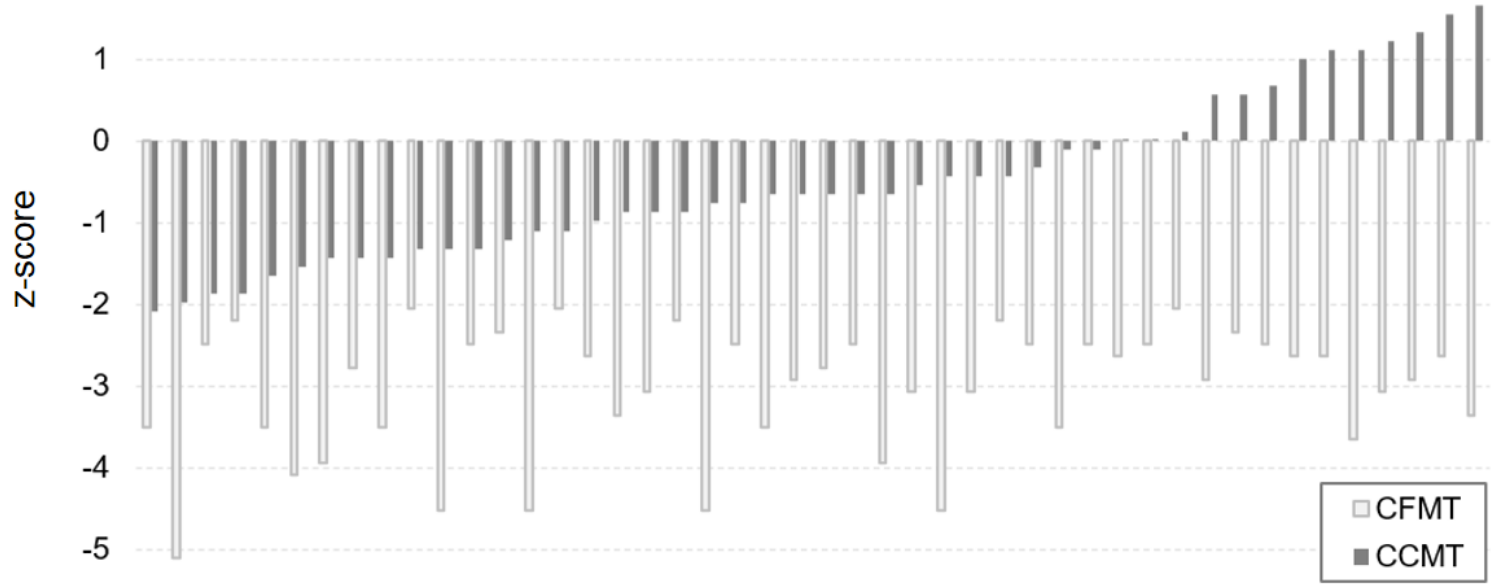

Figure 1: (a) Performance of the DPs and TDs on the CFMT and the CCMT. Error bars denote \pm 1 SEM. (b) Observers' scores on the CCMT plotted against their scores on the CFMT. (c) The relative performance of the 46 DPs on the CFMT and CCMT. 
Figure 2
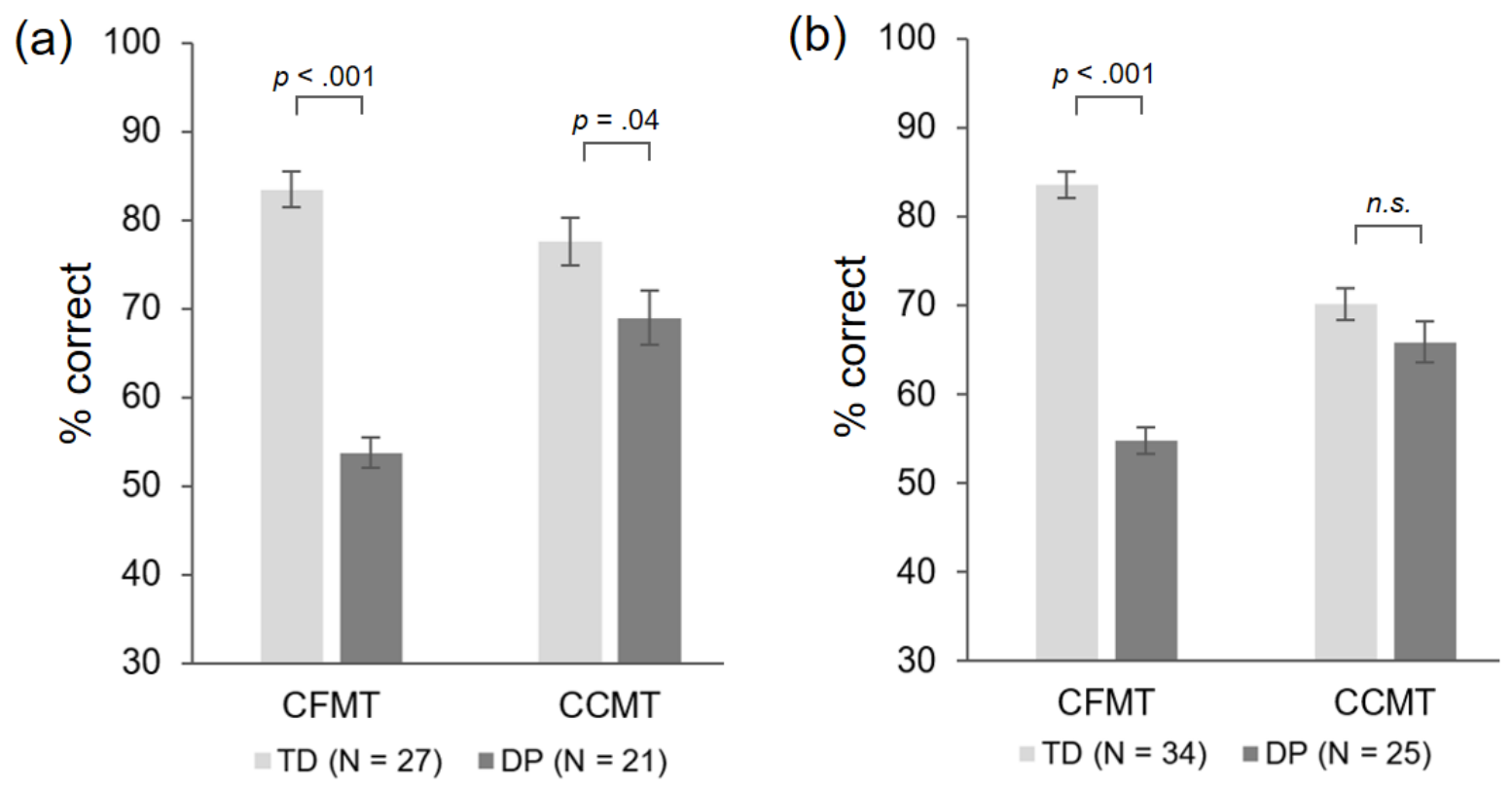

Figure 2: Performance of the male (a) and female (b) participants on the CFMT and CCMT. 


\section{Table 1}

Table 1: Diagnostic information for the DP and TD samples. Scores on the Cambridge Face Perception Test (CFPT) indicate the number of sorting errors made in the upright condition.

\begin{tabular}{llcc} 
& & Prosopagnosics (N = 46) & Typical controls (N = 61) \\
\hline PI20 & Mean (SD) & $82.04(5.84)$ & $38.03(8.59)$ \\
\cline { 2 - 4 } & Range & 70 to 94 & 20 to 57 \\
\hline \multirow{2}{*}{ CFMT } & Mean (SD) & $54.38 \%(7.39)$ & $83.56 \%(9.57)$ \\
\cline { 2 - 4 } & Range & $34.72 \%$ to 63.89\% & $62.50 \%$ to $100.00 \%$ \\
\hline CFPT & Mean (SD) & $52.39(16.20)$ & - \\
\cline { 2 - 4 } & Range & 26 to 88 & - \\
\hline
\end{tabular}

